Case report:

\title{
An Unusual Case of Acute Adrenal Insufficiency
}

\author{
Chanchal Das ${ }^{1}$, Pranab Kumar Sahana ${ }^{2}$, Nilanjan Sengupta ${ }^{3}$, Mukut Roy $^{4}$, Ranen Dasgupta ${ }^{5}$
}

\begin{abstract}
:
Empty Sella Syndrome (ESS) may be asymptomatic or manifested as features of multiple pituitary hormone deficiencies. In a patient of suspected hypopituitarism, multiple pituitary hormonal axes should be tested to rule out concomitant hormones deficiencies. In Hypopituitarism, treatment of hypoadrenalism should be undertaken first before giving levothyroxine replacement to prevent adrenal insufficiency.
\end{abstract}

Key Words: Hypopituitarism, adrenal insufficiency, ESS (Empty Sella Syndrome), Levothyroxine

\section{Introduction:}

Overt primary hypothyroidism is easy to diagnose, but central hypothyroidism may be missed if the treating physician has low index of suspicion in some cases of subclinical hypothyroidism. We are reporting a case of "primary hypothyroidism" with acute adrenal crisis.

\section{Case Report:}

A 45 years old male farmer presented with weakness, lethargy, dyspnea on exertion and loss of libido for six months. He was initially evaluated in the department of hematology for anemia and diagnosed to have hemoglobin E trait and subclinical primary hypothyroidism based on the hemoglobin electrophoresis and a single thyroid stimulating hormone $(\mathrm{TSH})$ of $6.1 \mathrm{uIU} / \mathrm{ml}$. Levothyroxine replacement was started at the dose of $100 \mathrm{ug} /$ day. Few months later, he developed fever with chills, loose motions and admitted in altered mental status in our hospital. On evaluation, he had hypotension with postural drop (sitting and standing blood pressure were 108/64 $\mathrm{mmHg}$ and $86 / 58 \mathrm{mmHg}$ respectively) and normal nervous system examination. Examination of secondary sexual characteristics revealed scanty beard,

1. Chanchal, Das, M.B.B.S(Cal), DCH(Cal), MD(Medicine), Post Doctoral Trainee (Endocrinology)

2. Pranab Kumar Sahana, MD(Medicine), DM(Endocrinology), Associate Professor

3. Nilanjan Sengupta, MD(Medicine), DM (Endocrinology), Associate Professor

4. Mukut Roy, M.B.B.S, MD(Medicine), Post Doctoral Trainee (Endocrinology)

5. Ranen Dasgupta, MD(Medicine), DM (Endocrinology), Professor \& Head

All the authors work in Department of Endocrinology, N.R.S. Medical College \& Hospital, Kolkata-700014, West Bengal, India

Corresponding Author:

Dr. Chanchal Das, M.B.B.S(Cal), DCH(Cal), MD(Medicine), Post Doctoral Trainee (Endocrinology), Department of Endocrinology, N.R.S. Medical College \& Hospital, Kolkata-700014, West Bengal, India, Email: drchanchal.das@gmail.com mustache, and axillary hair; testicular volume and phallic length were $15 \mathrm{ml}$ and $7 \mathrm{~cm}$ respectively. Complete hemogram revealed normocytic normochromic anemia with hemoglobin being $8.9 \mathrm{gm} / \mathrm{dl}$ and his plasma glucose was 68 $\mathrm{mg} / \mathrm{dl}$. Other routine biochemical parameters were within normal limits. Central hypothyroidism was diagnosed based on the very low free T4, free T3 and mildly elevated TSH level (Table 1).

Suspecting multiple pituitary hormone deficiency basal morning (9AM) serum cortisol, LH, FSH, IGF-1, and growth hormone were measured which showed all values were low (Table 1). Short co-syntropin stimulation test was performed which did not raise serum cortisol more than 20 ug/dl (Table 1).

Table 1: Showing values of different hormones with normal reference range

\begin{tabular}{|l|c|c|c|c|}
\hline Sl No & Item & Value & Normal range & Stressed value \\
\hline 1 & FT3 & $0.4 \mathrm{pg} / \mathrm{ml}$ & $(1.5-4.1) \mathrm{pg} / \mathrm{ml}$ & - \\
\hline 2 & FT4 0.2 & $\mathrm{ng} / \mathrm{dl}$ & $(0.8-1.9) \mathrm{ng} / \mathrm{dl}$ & - \\
\hline 3 & TSH & $6.9 \mathrm{uIU} / \mathrm{ml}$ & $(0.4-4.0) \mathrm{uIU} / \mathrm{ml}$ & - \\
\hline 4 & LH 0.41 & $\mathrm{mIU} / \mathrm{ml}$ & $(0.8-7.6) \mathrm{mIU} / \mathrm{ml}$ & - \\
\hline 5 & FSH & $0.34 \mathrm{mIU} / \mathrm{ml}$ & $(0.7-11.1) \mathrm{mIU} / \mathrm{ml}$ & - \\
\hline 6 & Cortisol $(9 \mathrm{AM})$ & $3.6 \mathrm{ug} / \mathrm{dl}$ & $(15-20) \mathrm{ug} / \mathrm{dl}$ & $>33 \mathrm{ug} / \mathrm{dl}$ \\
& $\begin{array}{c}\text { Short cosyntropin } \\
\text { stimulation test }\end{array}$ & $6.4 \mathrm{ug} / \mathrm{dl}$ & $>20 \mathrm{ug} / \mathrm{dl}$ & \\
\hline 7 & Basal GH & $2.2 \mathrm{ug} / \mathrm{L}$ & $<5 \mathrm{ng} / \mathrm{ml}$ & - \\
\hline
\end{tabular}

As he had biochemical evidence of panhypopituitarism, he was managed with intravenous hydrocortisone first along with other supportive measures. Then, levothyroxine replacement was also started. After stabilization of the patient, MRI of the brain was done which revealed primary partial empty sella with a small and grossly atrophic pituitary gland (Figure 1). 
Bangladesh Crit Care J September 2013; 1 (2): 107-108

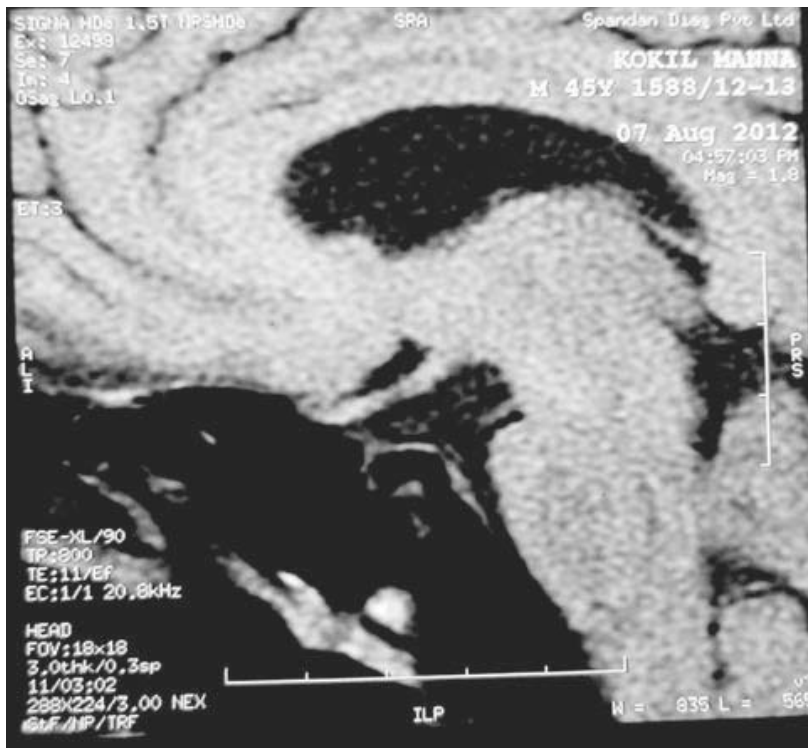

Figure 1: MRI of brain showing small and atrophic pituitary gland with partial empty sella

\section{Discussion:}

Patients with empty sella syndrome may be asymptomatic or may present with multiple pituitary hormone deficiencies. ${ }^{1}$ Hypothyroidism should not be diagnosed based on a single TSH value. TSH measurement is usually used as a screening test. Free T4 and free T3 along with $\mathrm{TSH}$ are required to differentiate primary and central hypothyroidism. In this case, central hypothyroidism was missed because free T3 and free T4 were not measured and TSH came above the normal reference range (Table 1). However, in the face of central hypothyroidism, mildly elevated TSH does not go against the diagnosis because $\mathrm{TSH}$ measured in this case may be immunoreactive but not bioactive. When a patient is having central hypothyroidism, we must look for concomitant other pituitary hormone deficiencies especially hypothalamo-pituitary-adrenal (HPA) axis should always be tested. ${ }^{2}$ Measurement of serum cortisol has got immense importance in the management of hypopituitarism. In a patient with very minimum adrenal reserve if levothyroxine is replaced, acute adrenal crisis may be precipitated. ${ }^{3}$ Patients with central hypothyroidism and impaired HPA axis, hydrocortisone should always be administered first followed by LT4 replacement. ${ }^{4}$

\section{Conclusion:}

Hypopituitarism should also be kept in mind and evaluated in a patient presented with mild hypothyroidism based on the TSH value alone. Free T4 should also be measured when TSH value is in the subclinical range. Paired hormone should always be interpreted in patients with thyroid dysfunction; otherwise central hypothyroidism may be missed. When there is deficiency of both thyroid hormone and cortisol, if thyroid hormone is replaced first without prior administration of corticosteroid, acute adrenal insufficiency may be precipitated.

\section{References:}

1. Malcolm J. Low. Neuroendocrinology.WILLIAMS Textbook of Endocrinology 12th Edition. ELSEVIER Saunders.2011. 7:112-183.

2. Rabkin MT \& Frantz AG. Hypopituitarism: a study of growth hormone and other endocrine functions. Annals of Internal Medicine 1966. 64: 1197-1207.

3. Van Aken MO, Lamberts SW. "Diagnosis and treatment of hypopituitarism: an update" 2005. Pituitary 8 (3-4): 183-91.

4. Lamberts SWJ, Bruining HA \& de Jong FH. Corticoid therapy in severe illness. New England Journal of Medicine 1997. 337: 1285-1292. 